\title{
Desdobramentos clínicos das propostas humanistas em processos de promoção da saúde
}

\section{Clinical unfoldings from humanistics proposals within health promotion processes}

\author{
Marcia Alves Tassinari*
}

Universidade Estácio de Sá - UNESA, Rio de Janeiro, Rio de Janeiro, Brasil

\begin{abstract}
RESUMO
O texto propõe uma articulação entre a concepção da Psicologia clínica contemporânea e seu desdobramento nos serviços de Plantão Psicológico. Apresenta-se um breve histórico da Psicologia Clínica, desde os primórdios da avaliação psicológica, passando pela compreensão clássica de clínica como tratamento psicoterápico, para delimitar a concepção atual de clínica ampliada e seu paradigma da promoção da saúde. Na comparação entre as dimensões patogênica e salutogênica, enfatiza-se a visão humanista, particularmente a proposta pela Abordagem Centrada na Pessoa, que mostra-se potente para lidar com o sofrimento humano em seus diferentes matizes de intensidade e profundidade. A autora apresenta as principais compreensões de Plantão Psicológico: como recepção, como triagem e como processo de atendimento à urgência psicológica. $O$ artigo aponta as potencialidades do diálogo como restaurador da saúde e atualizador da cidadania. A proposta da clínica ampliada mostra-se pertinente para acolher uma parcela significativa da população brasileira em diversos contextos.

Palavras-chave: Promoção da Saúde, Plantão Psicológico, Abordagem Centrada na Pessoa, Psicologia Clínica.
\end{abstract}

\begin{abstract}
This paper proposes a link between the conception of contemporary clinical Psychology and its unfolding within the services of psychological duty. It presents a brief history of clinical psychology since the early days of psychological assessment, through the clinical classical understanding as psychotherapeutic treatment, to define the current concept of amplified clinic and its paradigm of health promotion. In comparison between the pathogenic and salutogenic dimensions, it emphasizes the humanistic vision, particularly the one held by the Person-Centered Approach, which is powerful to deal with human suffering in its different shades of intensity and depth. The author presents the major understandings of psychological duty: as reception, assessment and as a process of emergency psychological care. The article points out the potential of dialogue as a restorer of health and citizenship updater. This proposal appears to be relevant to welcome a significant portion of the Brazilian population in different contexts.
\end{abstract}

Keywords: Health Promotion, Psychological Emergency Attendance, Person-Centered Approach, Clinical Psychology. 


\title{
1 Introdução
}

\author{
O quê esperamos nós quando desesperados, e \\ mesmo assim procuramos alguém? Esperamos \\ certamente uma presença por meio da qual nos é \\ dito que o sentido ainda existe. (BUBER)
}

A profissão de psicólogo no Brasil, regulamentada pela lei n. ${ }^{\circ} 4119$ de 27 de agosto de 1962, estabelecia três campos básicos de atuação: Clínico, Escolar e Industrial. Porém, ao longo do tempo esses campos foram sofrendo modificações para dar conta de novas demandas da contemporaneidade. Desde 2001, o Conselho Federal de Psicologia tem oferecido título de especialista em 11 modalidades, onde Psicologia Clínica é apenas uma delas, ainda que continue sendo o campo privilegiado dos psicólogos. (Resolução CFP 013/2007, que revoga as anteriores: no 014/00,02/01, 07/01, 03/02, 05/03, 02/04, 03/05, 04/05, 08/05, 013/05 e 014/05.)

A Psicologia vem ampliando seu raio de atuação para se inserir nas diversas instituições, além da saúde, como a jurídica, do esporte, comunitária, do trânsito, carecendo de um suporte teóricometodológico que oriente sua atuação.

O texto propõe uma articulação entre a concepção da psicologia clínica contemporânea e seu desdobramento nos serviços de pronto atendimento psicológico, ou plantão psicológico, visando a promoção da saúde em contextos diversos.

Para seguir esse percurso, será apresentado breve histórico da Psicologia Clínica, desde os primórdios da avaliação psicológica, com Wittmer, passando pela compreensão clássica de clínica como tratamento psicoterápico, a partir de Freud, para então delimitar a concepção atual de clínica ampliada e seu paradigma da promoção de saúde.

$\mathrm{Na}$ última parte, centro desta reflexão, apresenta-se a modalidade clínica dos atendimentos em Plantão Psicológico e sua inserção em diversos contextos, desconstruindo a visão clássica da clínica psicológica. O fechamento do artigo apresenta algumas provocações para futuras reflexões tanto da autora quanto dos leitores, que se sentirem instigados.

\section{Psicologia Clínica - breve histórico}

$\mathrm{Na}$ verdade podemos atribuir ao sofista Antífon, no século $\mathrm{V}$ a.C., a primeira intuição da escuta clínica psicológica, através da Techné Alupias. A sua techné, ou arte de tirar o desgosto, fundada na força da palavra ou dia logon (diálogo) consistia em aliviar o peso de grandes dores, restituindo um pouco de renovada serenidade, como 
se fosse uma intervenção de emergência, que ajudava a pessoa a perceber que estava agindo em desacordo com a sua natureza.

A denominação Psicologia Clínica foi utilizada pela primeira vez em 1896, por Lightner Wittmer, "para se referir aos procedimentos de avaliação que eram empregados com crianças retardadas e fisicamente deficientes" (MACKEY, 1975). A etimologia da palavra "clínica", de origem grega, remete ao significado "cama" e "inclinarse", designando os cuidados que o médico dispensa aos doentes acamados.

Desde o início percebemos a dimensão avaliadora nas definições de Psicologia Clínica, que apresenta a sua primeira formalização conceitual em 1935, através da divisão de Psicologia Clínica da Associação de Psicologia Americana, com a seguinte declaração:

\begin{abstract}
A Psicologia Clínica tem por finalidade definir as capacidades comportamentais e as características do comportamento de um indivíduo através de métodos de medição, análise e observação, e na base de uma integração desses resultados com os dados recebidos dos exames físicos e histórias sociais, fornece sugestões e recomendações com vistas ao apropriado ajustamento do indivíduo (MACKAY, 1975, p. 75).
\end{abstract}

A Psicanálise inaugura, na modernidade, a originalidade do "tratamento pela fala", aproximando a noção de clínica para tratar dos "problemas da alma", influenciando sobremaneira a Psiquiatria e a Psicologia. Esta passa a conceber a Clínica a partir do modelo médico, onde o profissional atuava como um expert e restringia-se a clientela oriunda de classes sociais favorecidas, com enfoque intrapsíquico, enfatizando os processos psicológicos e psicopatológicos, realizando psicodiagnóstico e psicoterapia individual e grupal (esta, mais raramente).

Vale ressaltar que na década de 40, surge nos EUA, o campo do Aconselhamento Psicológico (tradução inadequada para Counselling), inicialmente inserido nas escolas e centrado na avaliação e solução dos problemas de aprendizagem das crianças, disseminando-se para outras demandas, tornando frágil e sutil a distinção entre psicoterapia e aconselhamento.

O grande responsável por esta confusão conceitual foi Carl Rogers, que aproximou o aconselhamento da clínica psicológica, proposta por ele como trabalho de crescimento e não apenas como tratamento, centrado na pessoa que tinha o problema, com vistas a facilitar o crescimento, através de uma relação calorosa e incondicional. Rogers muda os principais eixos do Aconselhamento, aproximando-o da Psicoterapia, o que legitimou, na época, a psicoterapia como campo de atuação para os Psicólogos. (ROGERS, 2000).

A visão clássica da clínica psicológica atravessa algumas décadas, insinuando uma correspondência entre psicologia clínica apenas como 
psicoterapia individual, entendida como tratamento, realizado em consultório particular, por um profissional liberal, duas a quatro vezes por semana, por um período longo (de três a cinco anos), fundamentada preferencialmente na psicanálise. (TASSINARI, 2003)

Nota-se a urgência em questionar a identificação da primeira afirmação, pois Psicologia não se esgota no campo da Clínica. Essa é apenas uma das possibilidades de trabalho do psicólogo. Além da Clínica, temos diversos campos de atuação do psicólogo.

Identificar Psicologia Clínica com psicoterapia também empobrece a atuação do psicólogo clínico, que não se identifica com o local de trabalho (o consultório), mas que se constitui como um agente de mudança, contextualizado social, histórica e politicamente.

A segunda afirmação tradicional - de se considerar psicoterapia efetiva aquela realizada com uma única pessoa de cada vez (nível individual), durante um longo período, duas a quatro vezes por semana, fundamentada na Psicanálise - encontra-se inadequada frente aos desafios que a vida atual apresenta, além de não refletir o que muitos profissionais de fato já realizam.

A penetração da Psicologia em instituições diversas, especialmente trabalhando com grupos, aponta a necessidade de fortalecimento de novas teorias para que os psicólogos possam atuar, de forma efetiva, como agentes de mudança. Portanto considerar a psicoterapia, somente a diádica, novamente reduz as suas possibilidades de atuação e de alcance a uma população mais ampla. Os diferentes trabalhos já efetuados com grupos, tanto nos moldes de uma reconstrução de personalidade (psicoterapia extensiva) quanto com objetivos preventivos (grupos operativos, grupos de encontro, grupos reflexivos, trabalhos com e na comunidade etc.) confirmam 0 equívoco da frase. Vale ressaltar que estas críticas referem-se à formulação clássica das psicanálises, quando praticada apenas por médicos, com formação psicanalista (década de 70, no Brasil).

A última parte da equação - que considera a psicoterapia efetiva aquela realizada duas a cinco vezes por semana, por um longo período (de três a cinco anos), fundamentada na Psicanálise (e suas derivações) - também produz um reducionismo falso, obscurecendo as outras fundamentações teóricas, por exemplo, as psicoterapias humanistas, existenciais, comportamentais, cognitivas e transpessoais.

\section{Nova Concepção de Psicologia Clínica}

A concepção tradicional não resistiu às mudanças sócio culturais, sócio-políticas do país e as do próprio campo da Psicologia, propiciando uma nova compreensão da clínica psicológica para atender às demandas do contexto institucional, à ampliação do 
espaço no setor público, à necessidade do trabalho multi e interdisciplinar, ao estreitamento do vínculo da universidade com a comunidade, à necessidade de investigação. Estes vetores foram responsáveis pelo rompimento do modelo clássico (ACHCAR, 1994)

Oferecendo uma visão mais atualizada de Psicologia Clínica, Perez (1999), propõe:

"... sob tal perspectiva, a clínica não mais se refere a um
campo de atuação específico ou a uma modalidade da prática
de psicoterapia. O uso do termo 'clínica', passará a designar
a especificidade do trabalho do psicólogo, referindo-se a uma
forma de olhar os fenômenos que ultrapassa a obviedade dos
fatos e vai buscar no oculto, no não-dito, nas entrelinhas, a
interpretação intersubjetivamente construída e e
compartilhada, que confere significado e pertinência à
existência concreta" (p. 14).

O perfil de trabalho do psicólogo clínico brasileiro tem se modificado, para incluir áreas de atuação distintas da relação diádica em consultórios particulares, inclusive mudanças mesmo no interior dessa dimensão. A Psicologia Clínica está se adaptando ao homem de agora, da mesma forma que precisa abarcar uma concepção mais ampla de atendimento psicológico.

Dutra (2004) reitera o compromisso ético inerente ao papel do psicólogo clínico, implicando a vinculação do fenômeno clínico à dimensão social, quando afirma: "podemos dizer que o novo fazer clínico inclui uma análise do contexto social em que o indivíduo está inserido" (p. 382).

Guedes (1992), pesquisando a atuação do psicólogo clínico, apresenta a expansão desse profissional para o trabalho em instituições. Por outro lado, essa autora postula ser a "Psicologia Clínica a área que visa oferecer meios para as pessoas se conhecerem e perceberem suas próprias limitações e conflitos" ( $p$. 18). Portanto, identificar a atuação clínica com o local onde é exercida (o consultório), significa excluir a sua potencialidade nas instituições - especialmente as públicas (junto às populações carentes) - e complementando o trabalho através do intercâmbio com outros profissionais (equipe multi/trans/inter disciplinar).

Assume-se aqui o entendimento da Psicologia Clínica como pertencente à área da Saúde, com sua atuação no contexto social, podendo atuar também no nível preventivo (prevenção primária), utilizando-se de diferentes orientações teóricas, promovendo saúde em diversos contextos, além do consultório particular: hospital geral, hospital psiquiátrico, prisões, manicômio, creche, postos de saúde, escolas, favelas, trabalho com meninos e meninas de rua, com famílias vítimas de violência doméstica, nas varas de família, infância e juventude, somente para citar algumas de suas possibilidades 
atuais, convergentes com a nova Clínica Ampliada. (LO BIANCO, 1994)

\title{
4 A Clínica Ampliada
}

Em 2004, o Ministério da Saúde implementa o PNH (Projeto Nacional de Humanização), publicando a cartilha sobre a Clínica Ampliada, dentro do Projeto HumanizaSUS, reconhecendo assim que o fator humano estava ausente em nosso sistema de Saúde.

A Clínica Ampliada propõe que o profissional de saúde desenvolva a capacidade de ajudar as pessoas, não só a combater as doenças, mas a transformar-se, de forma que a doença, mesmo sendo um limite, não a impeça de viver outras coisas na sua vida. Na explicitação de suas metas, a cartilha afirma:

\begin{abstract}
Por humanização entendemos a valorização dos diferentes sujeitos implicados no processo de produção de saúde. Os valores que norteiam esta política são a autonomia e o protagonismo dos sujeitos, a co-responsabilidade entre eles, o estabelecimento de vínculos solidários, a participação coletiva no processo de gestão e a indissociabilidade entre atenção e gestão (p. 4).
\end{abstract}

Estas metas foram influenciadas indiretamente (já que não encontramos nenhuma referência direta) pelos princípios norteadores da Psicologia Humanista, especificamente aqueles propostos por Rogers desde a década de 40: singularidade, compromisso ético, responsabilidade, autonomia e diálogo com outros campos do conhecimento.

Esta clínica vê o doente primariamente como uma pessoa autônoma e digna de consideração, que necessita da escuta atenta do profissional de saúde. Esta pessoa, a partir da formação de vínculos com os diferentes representantes do sistema de saúde, vai se tornar ator e autor de sua vida, incluindo os cuidados com sua saúde, engajandose nos processos de promoção da saúde, orientações presentes na formulação da Psicologia Humanista na década de 60 (BOAINAIN, 1998).

Encontramos no CBO - Catálogo Brasileiro de Ocupações do Ministério do Trabalho a delimitação do trabalho do Psicólogo clínico, cujos pontos essenciais remetem a sua atuação na área específica da saúde ${ }^{1}$, para o exame de pessoas que apresentam problemas intra e interpessoais, de comportamento familiar ou social ou distúrbios psíquicos, e ao respectivo diagnóstico e terapêutica, empregando enfoque preventivo ou curativo e técnicas psicológicas a fim de contribuir para a possibilidade de o indivíduo elaborar sua inserção na vida comunitária. 
Este profissional acompanha programas de pesquisa, treinamento e política sobre saúde mental, elabora, coordena e supervisiona, para garantir a qualidade de tratamento em nível de macro e micro sistemas. Atua junto a equipes multiprofissionais identificando e compreendendo os fatores emocionais, para intervir na saúde geral do indivíduo em unidades básicas, ambulatórios, hospitais, partindo das questões concernentes à sua inserção social. (Resolução CFP 013/2007)

Propomos uma Psicologia Clínica Centrada na Pessoa comprometida com o contexto sócio-político-cultural das pessoas que são atendidas nos mais variados locais, mantendo sua especificidade enquanto escuta local (aos significados e sentidos implícitos) e, ao mesmo tempo, global (aos atravessamentos ambientais, sociais, políticos, religiosos, culturais, familiares, genéticos, físicos)

\section{Plantão Psicológico}

Uma rápida revisão do que tem sido denominado de Psicologia Clínica fez-se necessário, numa tentativa de limparmos a área, para nela incluir um tipo de escuta clínica, denominada de Plantão Psicológico. Este exige a escuta integral do outro no momento de sua indagação, requisitando não só uma atitude atenta ao desconforto emocional, mas também uma avaliação desse pedido de ajuda e seus atravessamentos (sociais, políticos, biológicos, ambientais). É nitidamente uma proposta que promove a saúde visto focalizar a necessidade de se cuidar, de ouvir atentamente o desconforto do outro para que ele possa também se ouvir de maneira translúcida.

A proposta inicial do Serviço de Plantão Psicológico surgiu em 1969, no Brasil (no Serviço de Aconselhamento Psicológico da Universidade de São Paulo), tendo sua primeira sistematização sido publicada somente no final da década de oitenta (ROSENBERG, 1987).

Uma primeira definição de Plantão psicológico é oferecida por Mahfoud (1987):

A expressão Plantão está associada a certo tipo de Serviço, exercido por profissionais que se mantêm à disposição de quaisquer pessoas que deles necessitem, em períodos de tempo previamente determinados e ininterruptos. Do ponto de vista da instituição, o atendimento de plantão pede uma sistematicidade do serviço oferecido. Do profissional, este sistema pede uma disponibilidade para se defrontar com o não planejado e com a possibilidade (nem um pouco remota) de que o encontro com o cliente seja único. E, ainda, da perspectiva do cliente significa um ponto de referência, para algum momento de necessidade" (p. 75). 
Tassinari (1999/2003) amplia esta definição, ao propor o Plantão Psicológico como um tipo de atendimento psicológico que se completa em si mesmo, realizado em uma ou mais consultas sem duração predeterminada, objetivando receber qualquer pessoa no momento exato (ou quase exato) de sua necessidade, para ajudá-la a compreender melhor sua emergência e, se necessário, encaminhá-la a outros Serviços. Tanto o tempo da consulta quanto os retornos dependem de decisões conjuntas do plantonista e do cliente, tomadas no decorrer da consulta.

É exercido por psicólogos que ficam à disposição das pessoas que procuram espontaneamente o Serviço, em local, dias e horários preestabelecidos, podendo ser implementado em diversos contextos e instituições.

O encaminhamento para a psicoterapia, para outros Serviços ou especialidades são objetivos secundários que não devem ocupar a atenção principal do plantonista. O plantonista e o cliente vão juntos procurar no "momento-já" as possibilidades ainda não exploradas que podem ser deflagradas a partir de uma relação calorosa, sem julgamentos, onde a escuta sensível e empática, a expressividade do plantonista e seu genuíno interesse em ajudar desempenham papel primordial.

Aprofundando este questionamento, Souza e Souza (2011) conclui: "As necessidades humanas e suas motivações podem ter um sentido emergencial para quem as vivencia e, nesse sentido, compreende-se o Plantão Psicológico como a clínica do acolhimento das urgências. (p. 247)

Ainda que o Serviço de Aconselhamento Psicológico da USP tenha completado 40 anos de atuação com o Plantão, este tipo de atenção clínica passa a se disseminar, por todo o Brasil, no final da década de 90.

Encontramos diversos contextos, onde tem sido criado Serviços de Plantão Psicológico: em clínica-escola de Psicologia, em consultório, em hospital geral (em diversos setores), em hospital psiquiátrico, em escola (desde o nível fundamental), em presídio, em delegacia, em comunidades de baixa renda, associados a projetos sociais, com meninos e meninas de rua, no tribunal regional do trabalho, no projeto esporte-talento, etc.

Souza \& Souza (2001) realizaram um excelente estudo a respeito das publicações sobre o Plantão Psicológico, no período de 1997-2009, revelando um quadro heterogêneo quanto à distribuição da produção científica nas bases de dados consultadas. A região sudeste apresenta maior concentração de publicações, com a maioria do trabalhos (de dissertação de mestrado) realizados em 2005 e 2006, apresentando a Abordagem Centrada na Pessoa como fundamentação teórica dominante. 
Acreditamos que esta preferência teórica não seja por acaso, mas que expresse a amplitude e a potencialidade desta Abordagem. Os psicólogos que se inspiram e utilizam esta abordagem sentem-se desafiados a responder às novas demandas da contemporaneidade e encontram no jeito de ser proposto por Rogers (1997; 1998/2008; 2000) e reorganizado por Wood (2008) como uma possibilidade potente.

Wood (Op.cit.) propõe a ACP como um jeito de ser (e não de fazer), permeado por sete aspectos interdependentes, a saber: uma perspectiva, de modo geral, positiva; uma crença numa tendência formativa direcional; uma intenção de ser eficaz; um respeito pelo indivíduo e sua autonomia e dignidade; uma flexibilidade de pensamento e ação; uma tolerância quanto às incertezas ou ambiguidades e senso de humor, humildade e curiosidade (p. 4).

Entendemos que o jeito de ser proposto por Wood (2008) a partir das condições necessárias e suficientes, propostas por Rogers (2008), formam 0 alicerce teórico-metodológico que norteiam o pronto atendimento conceituado em seguida como Plantão-processo ou Plantão Interventivo.

Das seis condições necessárias e suficientes, propostas por Rogers em 1957 (WOOD, 1998) e revisitadas no livro Um Jeito de Ser (1983), destacamos o conjunto atitudinal das condições de autenticidade, consideração positiva incondicional e compreensão empática, amplamente definidas na literatura rogeriana, que garantem a criação de um clima seguro e permeiam as intervenções no Plantão Psicológico.

Esta visão faz eco com Amatuzzi (2010), ao propor a Abordagem Centrada na Pessoa como uma ética: "... como uma maneira de ser que permite um determinado olhar e gera uma maneira de fazer." ( $p$. 58).

Os diferentes contextos aqui elencados apontam alguns tipos diferenciados de compreensão de uma escuta pontual. Na USP, inicialmente, ele foi concebido como recepção diferenciada aos clientes que procuravam o Serviço de Aconselhamento, o que foi, na época, uma alternativa para dar conta da imensa fila de espera.

Outras instituições que oferecem o Serviço de Plantão Psicológico objetivam uma recepção diferenciada à sua clientela, para avaliar a adequação da pessoa aos encaminhamentos futuros. Esse entendimento de Plantão aproxima-se da triagem rápida, visando encaminhamento para algum tipo de psicoterapia.

Vasconcelos (2009) em sua dissertação de mestrado, acrescenta o Plantão burocrático, como sendo aquele

que enfatiza o fator tempo e espaço para sua definição, reunindo assim características distintas da psicoterapia tradicional. Desta forma, o Plantão é definido como um 
espaço onde profissionais da psicologia estão disponíveis, em determinado tempo (normalmente turnos de atendimento), para quem os procurar, sem necessidade de marcação de consulta prévia. (p. 35)

Esta autora aponta também a possibilidade do Plantão-Focal, "como um espaço de ajuda pontual, para o cliente clarificar a natureza de seu sofrimento psíquico e depois encaminhá-lo para um serviço (psicoterapia individual, de grupos etc.) da clínica tradicional, eventualmente tendo alta." (p. 37). Este tipo funciona basicamente como uma triagem, cujo foco é o encaminhamento.

Privilegiado aqui, temos a modalidade de Plantão Interventivo (VASCONCELOS, 2009) ou Plantão-Processo (TASSINARI, 2003), onde a intenção básica é estar presente de maneira a acolher a pessoa numa escuta ativa, construindo em parceria um esclarecimento de seu pedido de ajuda, explorando as capacidades criativas de atualização. Esta modalidade, quando utilizada em contextos diferenciados de consultórios, exige uma flexibilização do setting terapêutico, em termos espaciais e temporais, além do deslocamento do centro de poder para a pessoa/grupo atendida/o.

\section{Considerações finais}

Essa modalidade de atenção psicológica permite alcançar, a curtíssimo prazo, um número significativo de pessoas que, de outra maneira não teriam possibilidades de serem acolhidas em seus sofrimentos.

Atender no momento exato ou quase exato da necessidade promove a saúde e amplia o exercício da cidadania. As possibilidades são enormes, da mesma forma que o são as dificuldades para sua implantação ao nível macro.

A proposta do Plantão Psicológico no acolhimento da urgência radicaliza a confiança no ser humano em seu potencial atualizador. Aqui seguimos a inspiração de Amatuzzi (Op.cit.): "Para uma pessoa se pentear, um espelho ajuda; para uma pessoa se conhecer melhor, um espelho humano é a melhor ajuda." (p. 63).

Nesse sentido, o Serviço de Plantão Psicológico aparece como uma atividade de promoção da saúde, já que a escuta do plantonista visa possibilitar que a pessoa se situe melhor naquele momento e consiga verbalizar sua urgência, clareando para si mesma aquilo de que necessita, podendo, portanto, evitar o acúmulo da ansiedade. Acreditamos que, ser atendida no momento de sua necessidade, por iniciativa própria, estimula o cuidado consigo mesma, atingindo, assim, os objetivos da prevenção primária. 


\begin{abstract}
Enquanto psicólogos não podemos nos esquecer, nem por um instante, da complexa rede que se estabelece quando nos relacionamos com outra pessoa com a intenção de nos tornarmos mais humanos (psicólogo e usuário) ao focalizarmos a singularidade da experiência. (TASSINARI, 2003, p. 125)
\end{abstract}

Schmidt (2004) nos alerta para a necessidade do apoio de políticas públicas mais amplas, de modo a possibilitar que os Serviços de Plantão possam responder à diversidade e singularidade das demandas que aparecem nos espaços institucionais públicos.

O reconhecimento dos avanços e da construção do conhecimento na última década a respeito do potencial do pronto atendimento dos Serviços de Plantão Psicológico não significa que o território já tenha sido totalmente explorado. Temos um longo e promissor caminho pela frente.

\title{
Referências
}

ACHCAR, R. (Coord.). Psicólogo brasileiro: Práticas emergentes e desafios para a formação. São Paulo: Casa do Psicólogo, 1994.

AMATUZZI, M. M. Rogers: Ética Humanista e psicoterapia. Campinas, SP: Alínea, 2010.

BOAINAIN, E. Tornando-se transpessoal: Transcendência e espiritualidade na obra de Carl Rogers. São Paulo, SP: Summus, 1998.

BRASIL. MINISTÉRIO DA SAÚDE. SECRETARIA-EXECUTIVA. Núcleo Técnico da Política Nacional de Humanização.

BRESCHIGLIARI, J.; ROCHA, M. C. (Orgs.). SAP - Serviço de Aconselhamento Psicológico: 40 anos de história. São Paulo: SAP/IPUSP, 2009.

Dicionário Petit Robert. Paris: Le Robert, 1990.

DUTRA, E. Considerações sobre as significações da psicologia clínica na contemporaneidade. Estudos de Psicologia, Natal, v. 9, n. 2, p. 381-387, 2004.

GUEDES, M. do C. Atuação do Psicólogo Clínico. Análise de dissertações em Periódicos Brasileiros e de Dissertações e Teses defendidas no país no período de 80/92. In: Conselho Federal de Psicologia. Psicólogo brasileiro: Construção de novos espaços. Campinas: Editora Átomo, 1992.

MINISTÉRIO DA SAÚDE; SECRETARIA-EXECUTIVA; NÚCLEO TÉCNICO DA POLÍTICA NACIONAL DE HUMANIZAÇÃO. Humanizasus: a clínica ampliada. Brasília: Ministério da Saúde, 2004. 18 p. - (Série B. Textos Básicos de Saúde)

LO BIANCO, A. C.; BASTOS, A. V. B.; NUNES, M. L. T.; SILVA, R. C. Concepções e atividades emergentes na Psicologia Clínica: 
Implicações para a formação. In: ACHCAR, R. Psicólogo brasileiro: Práticas emergentes e desafios para a formação. São Paulo: Casa do Psicólogo, 1994.

MACKAY, D. Psicologia clínica: Teoria e terapia. Rio de Janeiro: Zahar, 1975.

MAHFOUD, M. A vivência de um desafio: Plantão Psicológico. In: ROSENBERG, R. L. (Org.). Aconselhamento Psicológico Centrado na Pessoa. São Paulo: E.P.U., 1987.

MAHFOUD, M. (Org.). Plantão psicológico: Novos Horizontes. São Paulo: Companhia Ilimitada, 1999.

MORATO, H. P. T. (Org.). Aconselhamento psicológico centrado na Pessoa: Novos desafios. São Paulo: Casa do Psicólogo, 1999.

PEREZ, E. (1999) A Psicologia (e os psicólogos) que temos e a Psicologia que queremos: Reflexões a partir das propostas de diretrizes curriculares (MEC/SESU) para os cursos de graduação em Psicologia. Psicologia, Ciência e Profissão, Brasília, v. 19, n. 2, p. 10-19, 1999.

ROGERS, C. Tornar-se pessoa. (5a. ed.). São Paulo: Martins Fontes, 1997.

\section{Um Jeito de Ser. São Paulo, SP: Summus, 1983.}

Manual de counseling. Lisboa: Editora Encontro, 2000.

As condições necessárias e suficientes para a mudança terapêutica da personalidade. In: WOOD, J. K.; DOXSEY, J. R.; ASSUMPÇÃO, L. M.; TASSINARI, M. A.; JAPUR, M.; SERRA, M. A.; ROSENTHAL, R. W.; LOUREIRO, S. R.; CURY, V. E. (Orgs.). Abordagem centrada na pessoa. Vitória: Fundação Ceciliano Abel de Almeida/UFES, 2008.

ROSENBERG, R. L. (Org.). Aconselhamento psicológico centrado na pessoa. São Paulo: E.P.U, 1987.

ROSETI, L. Estratégias no tratamento das paixões (de Antifonte a Sócrates). HYPNOS, São Paulo, v. 14, n. 20, $1^{\circ}$ sem. 2008, p. 1-17, 2008.

SCHMIDT, M. L. S. Plantão Psicológico, Universidade Pública e Política de Saúde Mental. Estudos de Psicologia, Campinas, v. 21, n. 3, p. 173-192, 2004.

SEGRE, M. O conceito de saúde. Revista Saúde Pública, São Paulo, v. 31, n. 5, p. 538-542, 1997

SOUZA, B. N.; SOUZA, A. M. Plantão psicológico no Brasil (19972009) saberes e práticas compartilhados. Estudos de Psicologia, Campinas, v. 28, n. 2, p. 241-249.

TASSINARI, M. A. Plantão psicológico centrado na pessoa como promoção de saúde no contexto escolar. 1999. 149f. Dissertação (Mestrado em Psicologia), Universidade Federal do Rio de Janeiro, Rio de Janeiro.

TASSINARI, M. A. A clínica da urgência psicológica: contribuições da Abordagem Centrada na Pessoa e da Teoria do Caos. 2003. $231 \mathrm{f}$. 
Tese (Doutorado em Psicologia), Universidade Federal do Rio de Janeiro, Rio de Janeiro.

VASCONCELOS, T. P. de A atitude clínica no plantão psicológico: composição da fotografia experiencial do terapeuta-sherpa. 2009. 136f. Dissertação (Mestrado em Psicologia) - Universidade de Fortaleza, Fortaleza, CE.

WOOD, J. K.; DOXSEY, J. R.; ASSUMPÇÃO, L. M.; TASSINARI, M. A.; JAPUR, M.; SERRA, M. A.; ROSENTHAL, R. W.; LOUREIRO, S. R.; CURY, V. E. (Orgs.). Abordagem Centrada na Pessoa. UFES, Vitória, 2008.

\section{Endereço para correspondência \\ Marcia Alves Tassinari}

Universidade Estácio de Sá, Campus Norte Shopping, Av. Dom Hélder Câmara, 5080, Praça da Expansão, 3ำ piso, $4^{\circ}$ andar, Pilares, CEP: 20771004, Rio de Janeiro, RJ, Brasil

Endereço eletrônico: tassinari58@gmail.com

Recebido em: $14 / 10 / 2011$

Reformulado em: 13/08/2012

Aceito para publicação em: 20/10/2012

Acompanhamento do processo editorial: Ana Maria Lopez Calvo de Feijoo

\section{Notas}

*Psicóloga, Especialista em Psicologia Clínica, Doutora em Psicologia.

${ }^{1}$ Ainda que interessante, não temos espaço para discutir a concepção de Saúde, definida pela Organização Mundial da Saúde (OMS) como um completo estado de bem estar físico, mental e social e não meramente a ausência de doença (WHO, 1946). Esta concepção, avançada para a época, mostra-se desatualizada e é desconstruída e criticada por Segre (1997), provocando-nos em sua conclusão, ao propor: "saúde é um estado de razoável harmonia entre o sujeito e a sua própria realidade" (p. 542). Adotamos neste trabalho esta concepção provisória, indicando que a Psicologia Clínica dialoga com outros campos do saber, anteriormente restritos à Medicina. 